3 Fraga R, Franco FG, Roveda F, et al. Exercise training reduces sympathetic nerve activity in heart failure patients treated with carvedilol. Eur J Heart Fail 2007; 9: 630-636.

4 Ribeiro JP, Knutzen A, Rocco MB, et al. Periodic breathing during exercise in severe heart failure. Reversal with milrinone or cardiac transplantation. Chest 1987; 92: 555-556.

5 Naughton M, Benard D, Tam A, et al. Role of hyperventilation in the pathogenesis of central sleep apneas in patients with congestive heart failure. Am Rev Respir Dis 1993; 148: 330-338.
6 Yajima T, Koike A, Sugimoto K, et al. Mechanism of periodic breathing in patients with cardiovascular disease. Chest 1994; 106: 142-146.

7 Corra U, Giordano A, Bosimini E, et al. Oscillatory ventilation during exercise in patients with chronic heart failure: clinical correlates and prognostic implications. Chest 2002; 121: 1572 1580 .

DOI: $10.1183 / 09031936.00177209$

\title{
Smoking resumption after lung transplantation: a sobering truth
}

\section{To the Editors:}

About $40 \%$ of lung transplants (LTx) are performed for endstage emphysema in former smokers [1]. Patients are principally only enrolled on the waiting list after having quit smoking for at least 6 months [1]. Some LTx recipients may resume smoking, which could complicate post-transplant outcome [2]. Surprisingly, most LTx centres do not monitor smoking habits. We assessed all 267 LTx recipients currently in follow-up at our centre for smoking, after informed consent and approval by the local Ethical Review Board.

Smoking behaviour was investigated by a standardised questionnaire, measurement of urinary cotinine (COT) and exhaled carbon monoxide (eCO) levels. The questionnaire addressed past and current smoking habits (regular or occasional active smoking and second-hand smoking, i.e. passive exposure via relatives or environmental exposure via social/work-related contacts) as well as the use of nicotine-replacement therapy (NRT). COT was assessed by gas chromatography and mass spectrometry (Thermo Scientific, Geel, Belgium) and eCO by using an electrochemical sensor (Bedfont Scientific, Kent, UK; detection limit 1 ppm), as previously described [3, 4]. Statistical analyses were performed with Graphpad Prism 4.0 (San Diego, CA, USA). An unpaired t-test, Mann-Whitney U-test or Fisher's exact test were used where appropriate and receiver-operating characteristic curve analysis was used for calculation of predictive values.

LTx recipients (bilateral/single/heart-lung transplantation $\mathrm{n}=190 / 59 / 18)$ were assessed at a median (interquartile range) of 3.4 (1.5-6.0) yrs after LTx. Prior to LTx, 166 (62\%) out of 267 patients were former smokers and 101 (38\%) out of 267 neversmokers. Former smokers reported smoking cessation at a median of 4.0 (1.5-10.0) yrs before LTx. The majority of former smokers were transplanted for COPD ( $n=109$ out of $166,41 \%$ of the studied cohort), the remaining for pulmonary fibrosis $(10 \%), \alpha_{1}$-antitrypsin deficiency-related emphysema $(5.2 \%)$ or various other indications $(5.8 \%)$.

Based on the questionnaire, $30(11 \%)$ out of 267 patients reported ever smoking after LTx, of which, the majority had been transplanted for emphysema due to COPD $(n=25)$ or $\alpha_{1}$ antitrypsin deficiency $(n=2)$. Of these 30 patients, 27 were current active smokers at the time of evaluation ("smokers"). Three reported smoking only some cigarettes during a few weeks after LTx, but not at the time of evaluation, whereas the remaining 237 patients denied ever smoking after LTx ("nonsmokers"; $n=240$ ) (fig. 1). Second-hand smoking was reported in 105 (39\%) out of 267 patients, of whom 86 had smoking relatives (of which 40 smoked indoors), 31 regularly attended smokey bars and/or three worked in smokey conditions. The abstinence period between pre-LTx smoking cessation and subsequent LTx was shorter in smokers compared with nonsmokers: $1.0(0.5-2.0)$ versus 5.0 (2.011.0) yrs, respectively $(p<0.0001)$. Smokers resumed smoking at a median of $1.0(0.5-3.0)$ yr post-LTx and smoked 3 (2-5) cigarettes $\cdot$ day $^{-1}$. Smokers were more likely to be transplanted for emphysema (OR 17.5 (95\% CI 4.1-75.6); $\mathrm{p}<0.0001$ ), more

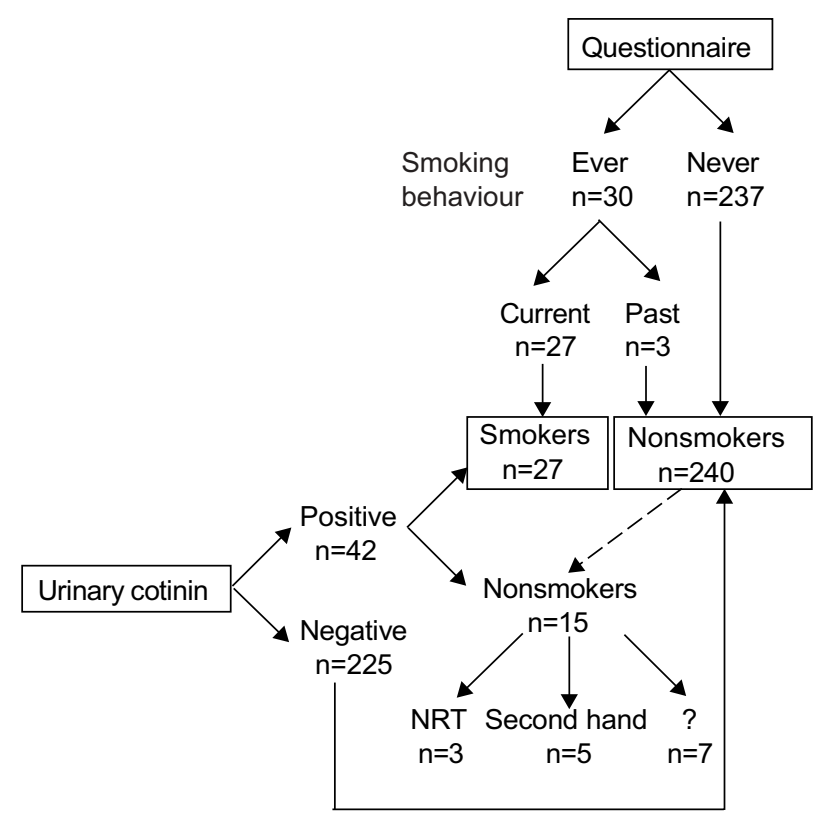

FIGURE 1. Flow-diagram of lung transplant recipients categorised according to reported smoking behaviour and urinary cotinin levels. NRT: nicotine-replacement therapy. 
recently transplanted $(p=0.036)$, more likely to be ever widowed (OR 4.7 (1.5-14.7); $\mathrm{p}=0.004)$ and had a lower socioeconomic status (OR $2.4(1.0-6.0) ; \mathrm{p}=0.048)$ compared with nonsmokers (table 1). Second-hand smoking was also higher in smokers compared with nonsmokers: $81 \%$ versus $35 \%$, respectively (OR $7.5(2.7-20.6) ; \mathrm{p}<0.0001)$. Median eCO levels were higher in smokers compared to nonsmokers: 8 (6-17) versus $3(2-4)$ ppm $(\mathrm{p}<0.0001)$. The optimal eCO cut-off for detecting current smoking was $4.5 \mathrm{ppm}$ (area under the curve (AUC) 0.82 (0.73-0.92), likelihood ratio 4.15; $\mathrm{p}<0.0001$ ) with a sensitivity and specificity of respectively 76.7 (70.9-81.9)\% and $81.4(61.9-93.7) \%$.

Using COT, 42 (16\%) out of 267 patients were identified as nicotine-exposed, of which 27 had admitted and 15 denied current smoking. Of the 15 patients denying smoking, positive COT could be explained by NRT $(n=3)$ or intensive secondhand smoking $(n=5)$, whereas in the minority $(n=7)$, no clear explanation was found. Of the 225 COT-negative patients, 222 patients had denied smoking and three reported temporarily smoking after LTx (as mentioned above). COT thus proved to be a sensitive marker for current smoking, with a sensitivity and specificity of 100.0 (95\% CI 98.4-100.0)\% and 64.3 (48.0$78.5) \%$, respectively. eCO levels were increased in patients with positive compared with negative COT: 6 (3-14) versus 3
$(2-4)$ ppm $(\mathrm{p}<0.0001)$, respectively. eCO was higher in the COT-positive patients admitting $(\mathrm{n}=27)$ compared with those denying $(\mathrm{n}=15)$ current smoking: $8(6-17)$ versus $3(2-5) \mathrm{ppm}$ $(\mathrm{p}=0.0009)$, respectively. In the 15 COT-positive patients denying smoking, eCO tended to be higher in the eight patients reporting NRT-use or second-hand smoking compared with the seven without a clear explanation for the positive COT: $4(3-8)$ versus $2(2-3)$ ppm $(\mathrm{p}=0.09)$. In general; the optimal eCO cut-off for a positive COT was again $4.5 \mathrm{ppm}$ (AUC 0.72 (0.63-0.81), likelihood ratio 2.02; $\mathrm{p}<0.0001$ ), with a sensitivity and specificity of 76.9 (70.9-82.3)\% and 61.9 (45.6$76.4) \%$, respectively.

The most remarkable finding is undeniably the high prevalence of post-LTx smoking, as 11\% of our LTx population and even $23 \%$ of the COPD patients admitted smoking resumption. Although this sobering truth may be shocking, these data are comparable to the $21 \%$ respectively $25 \%$ of heart and renal transplant recipients testing positive for posttransplant smoking [6, 7]. Risk factors for post-LTx smoking were a shorter pre-LTx smoking cessation period, emphysema, lower socioeconomic status, ever being widowed and passive smoking. Other established factors may furthermore indicate whether a smoker is more likely to resume smoking, such as an abstinence period of $\leqslant 6$ months, demographic (e.g. smoking at

TABLE 1 Characteristics of nonsmokers and smokers after lung transplantation

\begin{tabular}{|c|c|c|c|}
\hline Subjects $n$ & 240 & 27 & \\
\hline Male/female $n$ & $127 / 113$ & $12 / 15$ & 0.44 \\
\hline Type of Tx: B/S/HLTx $n$ & $168 / 55 / 17$ & $22 / 4 / 1$ & 0.45 \\
\hline Pre-LTx diagnosis of emphysema (COPD or $\alpha_{1}$-ATD)/other $n$ & $100 / 140$ & $25 / 2$ & $<0.0001$ \\
\hline \multicolumn{4}{|l|}{ Pre-LTx marital status $n$} \\
\hline Currently married/not-married & $150 / 190$ & $13 / 14$ & 0.69 \\
\hline Ever/never divorced & 29/211 & $6 / 21$ & 0.14 \\
\hline Ever/never widowed & $11 / 229$ & $5 / 22$ & 0.004 \\
\hline Pre-LTx alcohol consummation units week $^{-1}$ & $1.0 \pm 3.0$ & $0.7 \pm 2.1$ & 0.78 \\
\hline Time between pre-LTx smoking-cessation and LTx yrs & $5.0(2.0-11.0)$ & $1.0(0.5-2.0)$ & $<0.0001$ \\
\hline \multicolumn{4}{|l|}{ Post-LTx second-hand tobacco exposure } \\
\hline Negative/positive $n$ & $157 / 83$ & $5 / 22$ & $<0.0001$ \\
\hline From relatives/social/work-related contacts $n$ & $67 / 24 / 3$ & $19 / 7 / 0$ & 0.85 \\
\hline Time between LTx and assessment of smoking status yrs & $4.0(2.9-6.2)$ & $3.4(1.4-5.8)$ & 1.00 \\
\hline $\begin{array}{l}\text { Data are presented as } n \text {, median (interquartile range) or mean } \pm \mathrm{SD}, \mathrm{L} \\
\text { by means of a questionnaire. The } \mathrm{p} \text {-value was calculated using } \mathrm{M} \\
\text { regrouped patients into two socioeconomic levels only: low (Unem } \\
\text { professionals, executives, administrators and entrepreneurs). Lung } \\
\text { the LTx waiting list were excluded for analysis (for nonsmokers } 29 \text { ou } \\
\text { COPD: chronic obstructive pulmonary disease; } \alpha_{1} \text {-ATD: } \alpha_{1} \text {-antitryp } \\
\text { previous or current occupation at the moment of listing for } \mathrm{LTX} \text {, ba }\end{array}$ & $\begin{array}{l}\text { acteristics for nonsmo } \\
\text { values) or Fishers' e } \\
\text { killed and unskilled } \\
\text { were studying (at } m \\
\text { 26). Tx: transplant; B/s } \\
\text { omic status was asse } \\
\text { the British Registrar }\end{array}$ & $\begin{array}{l}40) \text { and smokers ( } \mathrm{n}= \\
\text { (proportions). For th } \\
\text { nd high (nonmanual } \\
\text { ol, high school or cc } \\
\text { lateral/single/heart- } k \\
\text { categorising patients } \\
\text { []. }\end{array}$ & $\begin{array}{l}\text { re identified } \\
\text { nt study, we } \\
\text { yees, clerks, } \\
\text { when joining } \\
\text { isplantation: } \\
\text { ding to their }\end{array}$ \\
\hline
\end{tabular}


an older age, earlier age at initiation, previous quit attempts) or psychological factors (e.g. stress/anxiety, degree of nicotine dependence) [8, 9]. Therefore, besides evaluating a patient's likelihood of smoking resumption, active screening for smoking, both when listed for LTx and during post-LTx follow-up, should be performed. For the patients resuming smoking, a standardised smoking cessation plan should be implemented. Patients' relatives, who most often continue smoking after LTx, must be recommended to stop smoking. At present, however, most LTx centres neither monitor smoking nor perform postLTx smoking cessation counselling.

The risk of smoking for worsening post-LTx outcome (i.e. by bronchiolitis obliterans syndrome, cancer or cardiovascular mortality) is currently unclear, yet long-term survival in heart transplantation is impaired by smoking due to chronic allograft rejection (graft coronary artery disease) [6]. Therefore, this ought to be investigated after LTx through a prospective study with repeated screening for smoking. The gold standard for screening, however, is currently unknown. Although a questionnaire is subjective; it has a good sensitivity/specificity to detect smoking and a good correlation with the COT test [10], a more objective assessment of the patient's nicotine-exposure [4, 11]. Despite being sensitive, COT conversely has a lower specificity as it may be falsely positive because of NRT or intensive second-hand smoking. False-negative values after pausing smoking are also possible as the half-life of COT is about $16 \mathrm{~h}$ [11]. False-negative tests could be prevented by repeated or unexpected COT tests. Although a lot less sensitive, eCO may be adequate to confirm the questionnaire or COT findings, but probably not to discriminate current from secondhand or nonsmokers as eCO may also be increased due to elevated airway neutrophilia after LTx [4].

In conclusion, the prevalence of post-LTx smoking is higher than generally assumed and active screening, both pre- and post-LTx, is crucial to detect smoking resumption. A standardised questionnaire and (preferably repeated) testing of COT is probably the best screening method. To confirm these findings we recommend eCO monitoring. Implementing a standardised smoking cessation plan after LTx must be considered. Finally, the importance of smoking resumption for the outcome after LTx should be investigated in a well-designed prospective study.

R. Vos* , K. De Vusser ${ }^{*}$, , V. Schaevers*, , A. Schoonis*, V. Lemaigre*, F. Dobbels*, K. Desmet", B.M. Vanaudenaerde*, D.E. Van Raemdonck*, L.J. Dupont* and G.M. Verleden*
*Lung Transplantation Unit, and "Laboratory Medicine, Katholieke Universiteit Leuven and University Hospital Gasthuisberg, Leuven, Belgium, "These authors contributed equally to the manuscript.

Correspondence: G.M. Verleden, Lung Transplantation Unit, University Hospital Gasthuisberg, 49 Herestraat, B-3000 Leuven, Belgium. E-mail: geert.verleden@uz.kuleuven.ac.be

Support Statement: This study is supported by the Research Foundation-Flanders (FWO G.0518.06, G.0643.08).

Statement of Interest: A statement of interest for G.M. Verleden can be found at www.erj.ersjournals.com $/ \mathrm{misc} /$ statements.dtl

\section{REFERENCES}

1 Verleden GM, Dupont LJ, Van Raemdonck DE, et al. Lung transplantation: a 15-year single-center experience. Clin Transpl 2007; 121-130.

2 Van der Heide F, Dijkstra G, Porte RJ, et al. Smoking behavior in liver transplant recipients. Liver Transpl 2009; 15: 648-655.

3 Zieliska-Danch W, Wardas W, Sobczak A, et al. Estimation of urinary cotinine cut-off points distinguishing non-smokers, passive and active smokers. Biomarkers 2007; 12: 484-496.

4 Vos R, Cordemans C, Vanaudenaerde BM, et al. Exhaled carbon monoxide as a noninvasive marker of airway neutrophilia after lung transplantation. Transplantation 2009; 87: 1579-1783.

5 Leete R, Fox AJ. Registrar General's social classes: origins and uses. Popul Trends. 1977; 8: 1-7.

6 Botha $\mathrm{P}$, Peaston $\mathrm{R}$, White $\mathrm{K}$, et al. Smoking after cardiac transplantation. Am J Transplant 2008; 8: 866-871.

7 Nguyen PT, Galanti L, Pirson Y, et al. Identification of current smokers among renal transplant recipients. Nephrol Dial Transplant 2007; 22: 1974-1978.

8 Caponnetto P, Polosa R. Common predictors of smoking cessation in clinical practice. Respir Med 2008; 102: 1182-1192.

9 Dobbels F, Verleden G, Dupont L, et al. To transplant or not? The importance of psychosocial and behavioural factors before lung transplantation. Chron Respir Dis 2006; 3: 39-47.

10 Molina AJ, Fernández D, Delgado $M$, et al. Sensitivity and specificity of a self-administered questionnaire of tobacco use; including the Fagerström test. Int J Nurs Stud 2010; 47: 181-189.

11 Benowitz NL. Clinical pharmacology of nicotine: implications for understanding, preventing, and treating tobacco addiction. Clin Pharmacol Ther 2008; 83: 531-541.

\section{New DNAH11 mutations in primary ciliary dyskinesia with normal axonemal ultrastructure}

\section{To the Editors:}

In primary ciliary dyskinesia (PCD; Mendelian Inheritance in Man database \#242650), a rare genetic disorder, the dysfunctional motility of cilia and impaired mucociliary clearance result in a myriad of clinical manifestations including recurrent infections of the respiratory tract, eventually causing lung damage, such as bronchiectasis, laterality defects and male infertility 